establish a general umbrella organization analogous to the American Chemical Society. Philip Pauly and Jane Maienschein dissect the two principal institutions at which C.O. Whitman worked the Marine Biological Laboratory at Woods Hole, Massachusetts, and the University of Chicago. These contributions are followed by five case studies of specialization within biology between about 1880 and 1920 , a period in which ethology, palaeontology, ecology, genetics and embryology each began to coalesce around key individuals, scientific issues or research strategies.

The collection as a whole is described as the centennial volume of the American Society of Zoologists, which may explain the absence of anything about botany. But it was a happy decision to celebrate a birthday by asking professional historians to write about the wider issues of discip- line and institution rather than the narrower administrative history of the society itself. Incidentally, the book was published in the year before the centennial. Somebody has been efficient.

Between them, these two volumes represent history of science at its modern best. Scientists will appreciate the extent to which cognitive issues are taken seriously, and historians will value the systematic exploitation of archival material in the placement of the science within its social, disciplinary or educational frameworks. A sociologist might note that, although editorial tasks have been shared, each essay has, with one exception, but a single author: historians of science, it seems, have not yet emulated the people they write about.

W.F. Bynum is at the Wellcome Institute for the History of Medicine, 183 Euston Road, London NWI $2 B P, U K$.

\section{History in science}

\section{A.G. Cairns-Smith}

Origins: The Darwin College Lectures. Edited by A.C. Fabian. Cambridge University Press: 1988. Pp. 168. £12.95, $\$ 19.95$.

ETERNAL truths there may be. But to explain the world is not only, and perhaps not ultimately, merely to seek laws of greater and greater generality. Things happen, and some of them leave their imprint. In the choice of connecting theme, these essays express a view of science - both ancient and very much late-twentieth-century modern — in which history has to be taken into account. The unexplained fundamentals in current theories are not only laws of nature, and so on, that just happen to be so, but events that just happen to have happened.

If physics traditionally seeks to concentrate ignorance into a limited set of laws, the next thought is to concentrate ignorance of history into a limited number of critical events or epochs - what we may call origins. Often this has been a way of (negatively) defining a field. Thus traditionally geologists did not have to know about the origin of the Earth, nor biologists about the origin of species or physicists about the origin of anything. Yet that heretic Darwin made sense of biology through speculating about origins (and finding instead a process). Astronomers and physicists are now intent on making sense of 'everything' by speculating about the origin of the Universe and again finding processes that seem to have brought key features into existence on different time scales. Martin Rees in the opening essay takes us back in imagination to the first $10^{-13} \mathrm{~s}$ or so where laws of physics themselves were coming into being. (Although he warns us that "Theorists differ in how far they are prepared to extrapolate back with a straight face".)

If the origin of our Universe and of our Earth might be said to be singular, with at least most of the creative work having come about in a relatively short time, other origins are much more plural and (like the origin of species) continuing. If I have picked up Ilya Prigogine's message on the origins (plural) of complexity correctly, there are critical but essentially unexplained events which are profusely scattered throughout time and on all scales from the supergalactic to the subatomic. Newtonian eternalism, or huttonian uniformitarianism or darwinian gradualism are not alternatives to the slings and arrows of chaos and catastrophe. They are approximations, useful within limits - places where the view is a little clearer, "windows" as Prigogine might say. Science can no longer do with defining away the rest of reality as its province because it is inconvenient.

Here too are hints as to how the 'hard' and 'soft' sciences will be integrated. They all (even physics) share elements of the eternal, the uniform, the gradual, the chaotic, the catastrophic. In the book we have a remarkably coherent set of essays, based on a series of popular lectures, which bring in physics, chemistry, the Earth's prehistory (David Hughes), and the evolution of man (David Pilbeam), of social behaviour (John Maynard Smith), of society (Ernest Gellner) and of language (John Lyons), as if they were all different parts of the same subject. Well, they are if you take science to mean, simply, trying to understand the world.

A.G. Cairns-Smith is in the Department of Chemistry, University of Glasgow, Glasgow G12 $8 Q Q$, UK.

\section{Animal rights and the apocalypse}

\author{
Mary Ann Elston
}

Animal Liberators: Research and Morality. By Susan Sperling. University of California Press:1988. Pp.247. \$19.95.

SINCE the mid-1970s, the 'animal rights' movement has developed into one of the most vigorous forms of social protest in Britain, the United States, Australia and many other countries, particularly those of northern Europe. Underlying its diverse manifestations is a common chal lenge to conventional moral boundaries, a challenge to the assumed rights of human beings to use and, by implication, abuse other animals to further human interests. Why such widespread concern over animals' moral status and suffering in general, and over animal experimentation in particular, has emerged in the late twentieth century in some Western societies is a question social scientists have been slow to take up. Susan Sperling's is one of the first book-length attempts to do so.

Sperling is an anthropologist whose academic career exemplifies to an unusual degree her discipline's concern with both the social and the natural world, and with the boundaries between them. She abandoned physical anthropology for primate behaviour studies, and then cultural anthropology for this study of how the boundaries between the social and the natural world are constructed in her own society and by her own discipline. Her concern is with animals as symbols, mediating human relationships with nature. Protest movements for 'animal rights' are, for her, not fundamentally protests about the suffering of non-human animals. Rather, they are protests about the human condition. Profound anxieties about scientific manipulation of the social and moral order are projected onto animals, specifically vivisected animals as both literal and figurative victims of scientific exploitation. Vivisection thus becomes the supreme evil in an apocalyptic vision of the future and abolishing it the key to achieving a harmonious millennium. The gulf between such zealots and those who seek merely more humane treatment of animals, let alone those who defend current scientific practice, is immense.

This thesis is based on a comparison of the American (or rather the San Francisco) 'animal rights' movement of the early 1980 s with the earlier apogee of organized antivivisection protest in latenineteenth-century Britain. Both periods, argues Sperling, were ones in which prevailing natural cosmologies were disturbed by the expansion of technological capacity and diffusion into popular culture 